\title{
Social Entrepreneurship: A New Driving Model for College Students Practicing Core Values
}

\author{
Yu Zhiwei, Chen Liming \\ Ningbo Institute of Technology, Zhejiang University \\ Ningbo, Zhejiang Province, 315100
}

\begin{abstract}
The lack of effective carriers leads to insufficient motivation for college students to practice socialist core values. On the basis of the in-depth analysis of the inherent consistency between social entrepreneurship and socialist core values, this paper puts forward a new driving model for college students' practicing core values by taking social entrepreneurship as the carrier and combines with the practice of Y-cube Public Welfare College, Ningbo Institute of Technology, Zhejiang University to make a detailed case study. The practice shows that college students can carry out the socialist core values in a more systematical and active way through the education and practice of social entrepreneurship.
\end{abstract}

Keywords-Social entrepreneurship; Socialist core values; Model; Practice

\section{INTRODUCTION}

The Report at 19th CPC National Congress proposes to "firmly establish the ideal of Communism and a common ideal of socialism with Chinese characteristics, and cultivate and practice the socialist core values."[1] The Opinions on Cultivating and Practicing the Socialist Core Values printed and issued by the General Office of the CPC Central Committee in December 2013 clearly stated to "integrate the cultivation and practice of the socialist core values into the whole process of national education" [2]; The General Secretary Xi Jinping emphasized the practicality and life of the socialist core values, and pointed out that: "we should pay attention to closely linking what we have advocated with the daily life of people and focusing on implementation it to the practice,"[3] This describes a blueprint for the college students to practice the socialist core values and provides them with directions and guidelines for practice [4].

How to guide the college students to internalize the socialist core values in the mind and externalize them into action is one of the hot theoretical issues and difficult issues for workers of philosophy and social sciences in recent years. Focusing on the carriers and ways in which the college students practice the socialist core values, scholars have put forward many insights from the aspects of ideological and political theory courses practice teaching, campus culture, social practice, voluntary service, emotional experience, life development, etc. [5] However, the actual effect of cultivating and practicing the socialist core values in domestic colleges and universities at present is not satisfactory. [6] The root cause lies in the lack of good carrier, making the college students lack the systematicness and driving force in the process of practicing the socialist core values.

This paper provides a model and practical framework for college students' practice of core values by taking social entrepreneurship as the carrier, and provides a new mode and path for expanding and broadening the practice of broadening the practice of core values. Firstly, this paper analyzes the consistency of the goals, contents and methods of social entrepreneurship education and core values; then, a new model for the practice of core values by taking the social entrepreneurship as the carrier is put forward. Finally, the actual effect for the college students' practice of core values that take the social entrepreneurship as the carrier is expounded by taking the practice of the Y-cube Public Welfare College, Ningbo Institute of Technology, Zhejiang University as a practical case.

\section{INHERENT CONSISTENCY BETWEEN SOCIAL} ENTREPRENEURSHIP AND SOCIALIST CORE VALUES

Deepening the innovation and entrepreneurship education reform is an important part of the state's promotion of "mass entrepreneurship and innovation" [7]. However, in the process of advancing innovation and entrepreneurship education, for one thing, the colleges neglect the cultivation of social responsibility for the students; for the other thing, there is a lack of systematic training for students' entrepreneurial innovation ability and business operation practice skills. Social entrepreneurship is a brand-new entrepreneurial model developed around the world in recent years, and its core idea is to solve social problems creatively by means of business practices [7-9], which has the "double bottom line" of entrepreneurship and sociality [10-12]. As social entrepreneurship education also emphasizes social responsibility and spiritual education[13] when it fosters the entrepreneurial awareness, spirits, knowledge, skills, and qualities of the educated people in order to achieve their allround development, it has already received the attention from and get practiced by some domestic universities (such as Hunan University). On the one hand, social entrepreneurship emphasizes that public welfare and social responsibility should be highly consistent with the socialist core values; on the other hand, it emphasizes to link with society extensively through practice so as to provide channels and carriers for practicing socialist core values. 
A. The goal of social entrepreneurship education is consistent with the cultivation goal of socialist core values.

Social entrepreneurship education can help college students establish a value system that is consistent with personal value and social entrepreneurship value; it can help college students master the process of social entrepreneurship and social innovation [13]. Its goal is to train the social responsibility of college students and to solve social problems with innovative thinking and business practices [14]. The core values emphasize "patriotism, dedication, integrity, and friendship", "freedom, equality, justice and the rule of law", and "prosperity, democracy, civility, and harmony" [2]. To cultivate and implement the core values is to train the social responsibility and sense of mission of college students, and set up the correct values. Through social entrepreneurship education, combining the concept of social entrepreneurship with the core value education, college students can integrate their personal value with the social value.

\section{B. The social entrepreneurship education and the cultivation of practicing socialist core values are highly compatible in contents.}

Social entrepreneurship education is guided by the social responsibility and the public welfare idea, and sets innovation and entrepreneurship education as an effective way to realize the social responsibility education. The contents can realize the combination of the employment with the entrepreneurship education, the material wealth creation with the spiritual wealth creation, as well as the self-value realization with social value creation. At the same time, social entrepreneurship education can be combined with ideological and political education, professional study, extra-curricular innovation activities and service society [13]. By participating in the study and practice of social entrepreneurship, college students will gradually pay close attention to national development and social problems, and promote their ability to solve social problems through business practices. This will promote the college students to seek for "patriotism, dedication, integrity, and friendship", pursue "freedom, equality, justice and the rule of law", and finally realize "prosperity, democracy, civility, and harmony". The contents of social entrepreneurship education have inherent consistency with the contents advocated by the core values.

\section{The social entrepreneurship is consistent with the core values in the cultivation ways and methods.}

Social entrepreneurship education emphasizes the combination of theory and practice [15], promotes students' experience, reflection, and application in their learning and practice, enhances social responsibility, and improves their ability to solve social problems. [16] This is highly consistent with the socialist core values pointed out by General Secretary $\mathrm{Xi}$ Jinping that "we must be integrated into social life so that people could perceive and comprehend them it in practice" [17]. Scholars have also successively discussed social practice [18-19], volunteer service [20-22], public welfare [5, 23-24] and so on as the carrier for college students to practice the core values. In contrast, the education and practice of social entrepreneurship sets solving social problems as the driving force to promote college students' active and systematic growth through effective means such as innovation and entrepreneurship, teamwork, in-depth docking with social resources and so on. Although the practice modes of the socialist core values are constantly enriched, as for using social entrepreneurship as the carrier to practice the socialist core values, college students are more in line with the requirements of practicing core values in terms of initiative and systemicity, which is more conducive to improving the effectiveness of the core values of college students [14].

College students' using social entrepreneurship as the carrier not only conforms to the trend of "mass entrepreneurship and innovation" but also is an important channel for enhancing their social responsibility and practicing core values. The author's unit set up the "Y-cube" Public Welfare College, carried out the "public welfare certification", provided organization and mechanism guarantee for the college students to practice the socialist core values by setting social entrepreneurship as the carrier, and further implemented the modes and practice for the college students to practice the socialist core values driven by social entrepreneurship.

\section{A Model For College Students PRActicing Core VALUES DRIVEN BY SOCIAL ENTREPRENEURSHIP}

The model for college students' practice of core values driven by social entrepreneurship refers to provide the students with what kind of platform and resources and to learn and practice in what way, so as to reach the common goal of social entrepreneurship and the practice of the core values, which is the intermediate link between theory and practice. In recent years, the team of the author has actively explored social entrepreneurship and the cultivation of the core values of college students, and gradually formed the talent cultivation concept of setting social entrepreneurship as the carrier, cultivating the college students' social responsibility, promoting the college students' innovation and entrepreneurial skills, learning and practicing the core values in the whole process of social entrepreneurship; On the basis of college students' public welfare association, set up the "Social Entrepreneurship Center" and "Y-cube" Public Welfare College and cooperate to establish the "Public Welfare Practice Base" so as to provide platform and organization support for college students to engage in social entrepreneurship and practice the core values; Integrate the theoretical course of social entrepreneurship and the practical course into the core curriculum system of relevant majors, and carry out the construction of the teaching content system [7]. Based on the teaching methods such as case learning, problem-based learning, project-based learning as guidance, carry out innovation to form the T-P-S (Team, Problem, Sharing) teaching method [25], and provide teaching method support for students. It has gradually formed "a new model for college students' practice of core values driven by social entrepreneurship" which sets the cultivation of innovation and entrepreneurial talents with social responsibility and the good atmosphere for actively practicing the socialist core values as the goals, taking the concept innovation as the guidance, using the platform and the organization as the support, regarding the core construction of the teaching contents as the main line, and 
taking teaching method reform and innovation as the means (as shown in Figure 1).

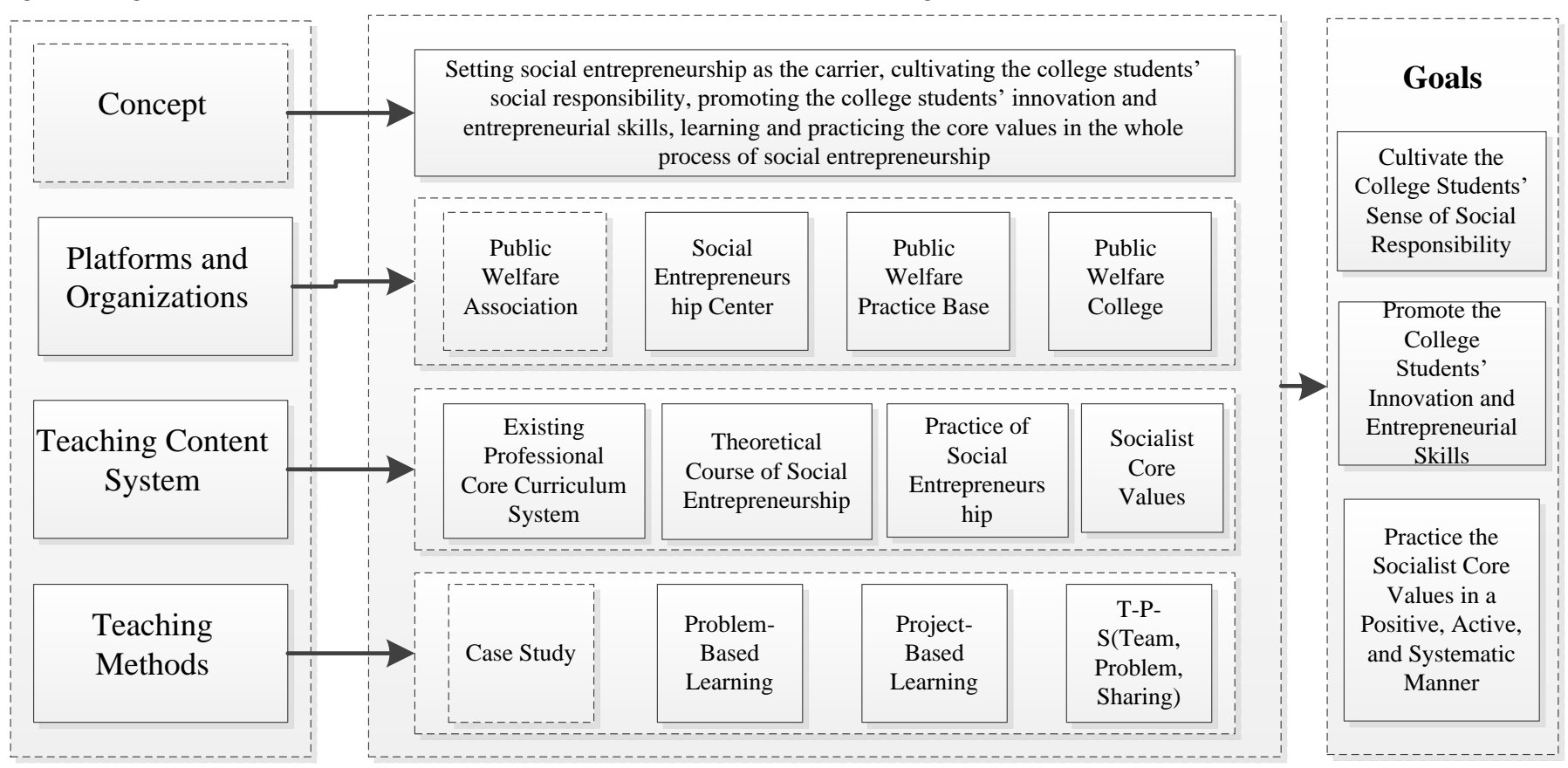

Fig. 1 A New Model for College Students Practicing Socialist Core Values Driven by Social Entrepreneurship

\section{A. Idea innovation}

On the one hand, college students can promote the cultivation and promotion of social responsibility by participating in public welfare, engaging in social entrepreneurship, and carrying out the cognition and practice of the socialist core values during the process of social entrepreneurship. On the other hand, it is beneficial to the training and cultivation of college students' innovation and entrepreneurial skills. In this way, by using social entrepreneurship as the carrier and solving social problems with commercial means, it has not only solved the problems of upgrading the innovation and entrepreneurial skills, but also practiced the core values in the social entrepreneurship learning and practicing, and has achieved the dual orientation of ability enhancement and core values practicing in concept.

\section{B. Mechanism innovation}

In order to provide organization guarantee, Social Entrepreneurship Center and "Y-cube" Public Welfare College have been set up successively at the time of maturity and Measures for Management of Public Welfare was launched, which encouraged the college students to participate actively from multiple dimensions such as competitions related to social entrepreneurship, project research, paper publication, activity participation, and project implementation practices, form standards and norms, and convert the participating activities into public welfare durations for public welfare certification, so as to promote the full participation of college students. It supports college students' public welfare association, carries out extensive and in-depth cooperation with all walks of life, and sets up public welfare practice bases, which have provided the three-dimensional support system for the public benefit certification, and founded a sustainable and systematic path for the college students to practice the socialist core values.

\section{Innovation in teaching content system and teaching method.}

At present, the "mass entrepreneurship and innovation" education of college students is in full swing, and the cultivation of core values has blossomed. However, there are still many practical problems in the theoretical framework and practical operation. In combination with the characteristics of social entrepreneurship and practicing the core values, take full consideration of the professional core curriculum, the theoretical course of social entrepreneurship, the practical system of social entrepreneurship, and the content system of practicing the core values, and combine the teaching methods such as teaching based on questions to form the innovation in T-P-S teaching models [24]. Cooperate with Ningbo Yinzhou Bank Foundation to set up the social entrepreneurship class, open the optional course, The Practice of Social Entrepreneurship, orienting towards all the students of the college, and conduct theoretical teaching and contest counseling in social entrepreneurship. Through social entrepreneurship education, the comprehensive skills of college students' innovation and entrepreneurship get promoted, the ability of the college students to identify, analyze and solve the social problems gets improved, and the core value cognition is gradually enhanced in the whole process of social entrepreneurship. The daily life and learning are integrated into the practicing process of socialist core values. 


\section{The EFFECT OF COllege Students Practicing SOCIALIST CORE VALUES DRIVEN BY SOCIAL ENTREPRENEURSHIP}

Driven by social entrepreneurship, Ningbo Institute of Technology, Zhejiang University, carried out extensive indepth cooperation with all walks of life to enhance the social responsibility of college students and achieve the good momentum of practicing the core values in the whole process of social entrepreneurship through innovating the ideas, providing the organization guarantee, as well as innovating the teaching methods and the teaching content system.

\section{A. Using social entrepreneurship to drive college students to practice socialist core values began to reach a certain scale}

Since the school combines the social entrepreneurship education with the professional education, the school-wide public optional courses, the school-wide social entrepreneurship contest and the training, the cultivation and practice of socialist core values driven by the social entrepreneurship has reached a wide range of coverage rapidly. Social entrepreneurship education was piloted at the Business School, Ningbo Institute of Technology, Zhejiang University, which made social entrepreneurship education benefit all the students in the Business School through the public welfare certification mechanism; The Essence of Business Ethics, Marketing of Public Welfare Organizations and other courses are integrated into the professional training program, and the public optional course, The Practice of Social Entrepreneurship, orienting towards all the students of the college is set up; Through the social entrepreneurship competition, the social entrepreneurship practice activities, most of the college students were attracted to participate. In the guidance and integration of the concept of social entrepreneurship education and the concept of core values, we combine with the Party class, the public welfare practice and the social entrepreneurship sharing meeting, as well as all kinds of innovation and entrepreneurial competitions at all levels to carry out. The use of social entrepreneurship to drive college students to practice socialist core values has exceeded one-third of all students in Ningbo Institute of Technology, Zhejiang University, and will gradually realize a wide coverage in the whole school.

\section{B. The systematization of college students' practice of socialist core values by social entrepreneurship has been strengthened}

In contrast to the cultivation of common socialist core values, social entrepreneurship emphasizes that the college students should systematically learn to recognize social problems, analyze social problems, propose solutions, integrate social resources, and put the ideas into practice and other systematic learning and growth processes, so as to understand and practice core values in learning and growth. In the process of social entrepreneurship education, college students not only need to study relevant theories, design social problems and solutions, and participate in the social entrepreneurship contest, but also need to put ideas into practice through building a team and systematically provide cognitive and operational opportunities for the practice of core values throughout the process. "Y-cube" Public Welfare College, Ningbo Municipal Bureau of Civil Affairs, Bureau of Civil Affairs at all districts and a large number of grass-roots organizations carry out social entrepreneurship cooperation, which provides rich and diverse learning and practical platform for college students to practice the socialist core values through social entrepreneurship. As for the college students' practice of socialist core values by taking social entrepreneurship as the carrier, the college students are systematically growing through the theoretical study, participation in competition and landing practice in the whole process, which is also the systematic new path for the implementation of the socialist core values.

\section{The enthusiasm and initiative of the college students to carry out the socialist core values during the whole process of participating in the social entrepreneurship are enhanced}

In addition to carrying out public welfare certification, "Ycube" Public Welfare College cooperates with Ningbo Yinzhou Bank Foundation to set the cultivation of the young leading talents in the field of social entrepreneurship as the goal, construct the "Y-cube" social entrepreneurship class, and also actively promote the college students to participate in the competitions related to all kinds of social entrepreneurship, so as to provide support for the incubation and landing of college students' social entrepreneurship projects, which has greatly enhanced the enthusiasm and initiative of the college students. In recent years, students have been awarded 100 prizes for various innovation and entrepreneurship projects at the national and provincial level. More than ten projects such as "Silver Nest" active pension public welfare projects have been supported by public welfare venture capital and have been serving the society through incubation. Through learning, participation, project incubation and social services, use "certificate", "honor", "growth", and "service to the society" to motivate and promote the college students to upgrade their individual values of "patriotism, dedication, integrity, and friendship "and put them into practice so as to achieve the goal of realizing "freedom, equality, justice and the rule of law" of the whole society and "prosperity, democracy, civility, and harmony". Guided by solving the social problems, it can not only upgrade the innovation and entrepreneurship skills in the whole process, but also can promote the college students' to form a team to do "meaningful things", which greatly enhanced the college students' enthusiasm and initiative to practice the socialist core values in the whole process of participating in the social entrepreneurship.

\section{CONCLUSIONS}

In this paper, the reason why the effect of cultivating and practicing the core values in domestic colleges and universities was not satisfactory was analyzed. Based on the analysis between social entrepreneurship and socialist core values, a new driving model for college students' practice of social core values was put forward by taking social entrepreneurship as the carrier. In the new model, the idea innovation, the mechanism innovation, the innovation in teaching content system and teaching method supported the core process of practicing core 
values by engaging in social entrepreneurship. Finally, The effect for college students' practice of social core values was shown as (1) using social entrepreneurship to drive college students to practice socialist core values began to reach a certain scale, (2) the systemic nature of using social entrepreneurship to drive college students to practice socialist core values has been strengthened, and (3) the enthusiasm and initiative of the college students to carry out the socialist core values during the whole process of participating in the social entrepreneurship are enhanced.

\section{ACKNOWLEDGEMENT}

This paper is about the stage results of the special task project in humanities and social sciences conducted by the Ministry of Education (Study on the Theoretical System of Socialism with Chinese Characteristics), "Study on the Network Communication Strategy of Socialist Core Values" (Project Approval No.: 15JD710071) and the special project in humanities and social sciences conducted by the Ministry of Education (Special Ideological and Political Projects in Colleges and Universities), "Study on the 'Miniaturization' of Socialist Core Values for College Students" (Project Approval No.: 16JDSZ1010) and the project from the Ningbo strategic office cooperation with Chinese Academy of Social Sciences (\#NZKT201527).

Profile of the Author: Yu Zhiwei (1978- ), male, born in Linchuan, Jiangxi Province, Associate Professor, engaged in research and practice related to social entrepreneurship. Chen Liming (1971- ), male, born in Hangzhou, Zhejiang Province, Master, Minister of the Publicity Department of Ningbo Institute of Technology, Zhejiang University.

\section{REFERENCES}

[1] Whole text of the Report at 19th CPC National Congress [EB/OL].http://www.spp.gov.cn/tt/201710/t20171018_202773.shtml, 2017.10.18

[2] The Opinions on Cultivating and Practicing the Socialist Core Values Printed and Issued by the General Office of the CPC Central Committee [EB/OL]. http://cpc.people.com.cn/n/2013/1223/c64387-23924110.html, 2013-12-23

[3] Xi Jinping. Setting the cultivating and carrying forward the socialist core values as the fundamental project of promoting cohesion, solidifying the base and reinforcing the foundation [N], People's Daily, February 26, 2014, First Edition.

[4] Niu bing. The analysis of the path of cultivating and practicing the socialist core values in colleges and universities [J]. Theory Research, 2017, (01): 241-242.

[5] Guo Chao. Leading College Students to Practice Socialist Core Values in Micro-public Welfare [J]. Journal of Suzhou University of Science and Technology (Social Science), 2017, 34(04):92-96+108.

[6] Guo Chaohui. Research on the Cultivation and Practice of Socialist Core Values for College Students [D]. China University of Mining and Technology, 2015
[7] Li Pingping. Social Entrepreneurship: Driving a New Type of Innovative Entrepreneurial Talent Cultivation [N], Ningbo Daily, August 3, 2017, 10th Edition.

[8] Leadbeater, C. The Rise of the Social Entrepreneur[M].London : Demos, 1997.

[9] Dees. The Meaning of Social Entrepreneurship[R]. Comments and Suggestions Contributed form the Social Entrepreneurship Funders working Group. 1998.

[10] Johanna Mair, Ignasi Martí. Social Entrepreneurship Research: A Source of Explanation, Prediction, and Delight[J], Journal of World Business, 41(2006), p. 36-44.

[11] Ana Marı'a Peredo, Murdith McLean. Social Entrepreneurship: A Critical Review of the Concept[J]. Journal of World Business, 41 (2006) 56-65

[12] Kazuhiko Mikami,An Alternative Framework for the Analysis of Social Enterprises[EB/OL] . Journal of Co-operative Organization and Management 2 (2014): 92-97.

[13] Tang Yayang, Deng Yingwen \& Wang Zhong. Social Entrepreneurship Education in Colleges and Universities: Concept, Practical Significance and System Construction [J]. University Education Science, 2015, Issue 5 (General 129): 49-53

[14] Guo Ying \& Li Tao. Social Entrepreneurship Education: A New Carrie for the College Students' Socialist Core Values Education [J]. Labor Security World, 2016(30):24-25

[15] Tang Yayang. Introduction to Social Entrepreneurship [M]. Changsha: Hunan University Press, 2009:68.

[16] Xu Xiaozhou \& Ni Hao. Social Entrepreneurship Education: The Experience and Revelation of Harvard University [J], Educational Research, 2016 (01):143-149

[17] Xi Jinping. Xi Jinping: The Governance of China [M]. Beijing: Foreign Languages Press, 2014

[18] Jinyao \& Chen Huzhou. On Social Practice and College Students Socialist Core Values Education [J]. Journal of Hebei Normal University for Natinalities, 2014, 34(04): 101-104.

[19] Guan Cui' e. On the Role of Social Practice in Promoting College Students' Socialist Core Values Education [J]. Journal of Hubei Institute of Socialism, 2017(02): 90-93.

[20] Yang Jun. Volunteer Activities: A Breakthrough in the Cultivation of Socialist Core Values in Colleges and Universities [J]. Education Research Monthly, 2011(10): 40-42.

[21] Li Xin. Research on the Cultivation of Volunteer Spirits and Socialis Core Values in Colleges and Universities [J]. Science \& Technology Information, 2014, 12(28): 231

[22] Shen Guihua. On the practice of Volunteer Activities and Socialist Core Values in Colleges and Universities [J]. Management Observer, 2016 (07):151-153

[23] Zhou Zhongzhi. The Cultivation and Practice of Charitable Public Welfare and Socialist Core Values [J]. Ideological \& Theoretical Education, 2015(6):21-25.

[24] Li Yang \& Han Ying. Research on the Cultivation Mechanism of College Students' Public Welfare Spirits under the Guidance of the Socialist Core Values [J]. Journal of Ideological and Theoretical Education, 2016 (5): 105-108.

[25] Yu Z, Alex R. A Share Learning Framework for Innovation Education: Improving Creative Thinking Capability from Daily Life [J]. Procedia Computer Science, 2014, 31:359-368. 